ARTICLE

\title{
Oxidative 1,2-carboamination of alkenes with alkyl nitriles and amines toward $\gamma$-amino alkyl nitriles
}

Yan-Yun Liu ${ }^{1,2, \star}$, Xu-Heng Yang ${ }^{1,2, \star}$, Ren-Jie Song ${ }^{1,2}$, Shenglian Luo ${ }^{1,2} \&$ Jin-Heng Li $i^{1,2,3}$

Difunctionalization of alkenes has become a powerful tool for quickly increasing molecular complexity in synthesis. Despite significant progress in the area of alkene difunctionalization involving the incorporation of a nitrogen atom across the $\mathrm{C}-\mathrm{C}$ double bonds, approaches for the direct 1,2-carboamination of alkenes to produce linear $\mathrm{N}$-containing molecules are scarce and remain a formidable challenge. Here we describe a radical-mediated oxidative intermolecular 1,2-alkylamination of alkenes with alkyl nitriles and amines involving $\mathrm{C}\left(s p^{3}\right)-\mathrm{H}$ oxidative functionalization catalysed by a combination of $\mathrm{Ag}_{2} \mathrm{CO}_{3}$ with iron Lewis acids. This three-component alkene 1,2-alkylamination method is initiated by the $\mathrm{C}\left(s p^{3}\right)-\mathrm{H}$ oxidative radical functionalization, which enables one-step formation of two new chemical bonds, a $\mathrm{C}-\mathrm{C}$ bond and a $\mathrm{C}-\mathrm{N}$ bond, to selectively produce $\gamma$-amino alkyl nitriles.

\footnotetext{
${ }^{1}$ Key Laboratory of Jiangxi Province for Persistent Pollutants Control and Resources Recycle, Nanchang Hangkong University, Nanchang 330063, China.

${ }^{2}$ State Key Laboratory of Chemo/Biosensing and Chemometrics, Hunan University, Changsha 410082, China. ${ }^{3}$ State Key Laboratory of Applied Organic Chemistry, Lanzhou University, Lanzhou 730000, China. * These authors contributed equally to this work. Correspondence and requests for materials should be addressed to S.L. (email: sllou@hnu.edu.cn) or to J.-H.L. (email: jhli@hnu.edu.cn).
} 
$\mathrm{D}$ ifunctionalization of alkenes represents one of the most powerful and straightforward tools to build complex molecules via one-step construction of two chemical bonds that possess significantly synthetic utility in chemical synthesis ${ }^{1-6}$. One of the major synthetic targets for such transformations, including diamination ${ }^{7-15}$, aminooxygenation ${ }^{16-24}$, aminohalogenation ${ }^{25-30}$ and carboamination ${ }^{31-36}$, is the incorporation of a nitrogen atom (amino, amide or azide groups) across the C-C double bonds to build useful $\mathrm{N}$-containing molecules through the formation of a $\mathrm{C}-\mathrm{N}$ bond. Despite significant progress in the field, approaches of the alkene carboamination for producing linear $\mathrm{N}$-containing molecules are scarce and remain a great challenge (Fig. 1a): available intermolecular transformations for producing linear $\mathrm{N}$-containing molecules are restricted to the special amination reagents ${ }^{33-36}$. Further, to our knowledge, three-component carboamination reactions of the alkenes via $\mathrm{C}-\mathrm{H}$ functionalization have never been reported.

In recent years, the $\mathrm{C}-\mathrm{H}$ oxidative functionalization reaction has attracted much attention due to its inherent features, such as high step economy and atom economy ${ }^{1-6,37-41}$. Typical transformations include the difunctionalization of alkenes with alkyl $\mathrm{C}\left(s p^{3}\right)-\mathrm{H}$ bonds $\mathrm{s}^{42-55}$ and the majority of which rely on the formation of a $s p^{3}$-hybridized carbon-centred radical from the oxidative cleavage of the corresponding alkyl $\mathrm{C}\left(s p^{3}\right)-\mathrm{H}$ bond followed by addition across the C-C double bond ${ }^{43-59}$. However, such approaches are restricted to the 1,2-arylalkylation ${ }^{52-63}$, 1,2-dialkylation ${ }^{54}$ and 1,2-oxyalkylation ${ }^{55-59}$ of the alkenes, and the available three-component transformations are scarce ${ }^{53,55}$. In light of these literature results $3^{43-59}$ and our continuous interest in oxidative radical reactions ${ }^{60-63}$, we envisioned that this $\mathrm{C}-\mathrm{H}$ oxidative radical functionalization strategy might be viable to achieve 1,2-carboamination of alkenes with new-conceptual, general and straightforward features.

Herein, we report an iron-catalysed oxidative three-component 1,2-carboamination of alkenes with alkyl nitriles and amines through $\mathrm{C}\left(s p^{3}\right)-\mathrm{H}$ oxidative radical functionalization to assemble $\gamma$-amino alkyl nitriles using $\mathrm{Ag}_{2} \mathrm{CO}_{3}$ as oxidant (Fig. 1b). The reaction enables the simultaneous formation of two new chemical bonds, a $\mathrm{C}-\mathrm{C}$ bond and a $\mathrm{C}-\mathrm{N}$ bond, by a sequence of $\mathrm{C}-\mathrm{H}$ oxidative cleavage, radical addition across the alkenes and aminationin a highly atom-economic and selective manner ${ }^{64-68}$.

\section{Results}

Reaction optimization. We initiated the study by investigating various reaction parameters for the three-component reaction of $p$-methoxystyrene (1a) with acetonitrile (2a) and dibenzylamine (3a) (Table 1). A combination of $10 \mathrm{~mol} \% \mathrm{Fe}(\mathrm{OTf})_{3}, 2$ equiv $\mathrm{Ag}_{2} \mathrm{CO}_{3}, 120^{\circ} \mathrm{C}$ and $24 \mathrm{~h}$ were found as the optimal reaction conditions for the conversion of alkene 1a, nitrile $\mathbf{2 a}$ and amine $3 \mathbf{a}$ to the desired product 4 in $82 \%$ yield (entry 1). The results suggest that $\mathrm{Ag}_{2} \mathrm{CO}_{3}$ is the real catalysts and $\mathrm{Fe}(\mathrm{OTf})_{3}$ only serves as a Lewis acid to promote the reaction (entries 2 and 3): although in the absence of $\mathrm{Fe}(\mathrm{OTf})_{3}$ transformation of alkene $2 \mathrm{a}$ to 4 took place albeit giving a lower yield (entry 2), no desired reaction was observed without Ag salts (entry 3). Other Ag salts, including $\mathrm{Ag}_{2} \mathrm{O}, \mathrm{AgOAc}$ and $\mathrm{AgNO}_{3}$, had the catalytic activity for the reaction, but they were less effective than $\mathrm{Ag}_{2} \mathrm{CO}_{3}$ (entries 4-6). Among the amount of $\mathrm{Ag}_{2} \mathrm{CO}_{3}$ examined, the use of 2 equiv was turned out to be preferred (entries 1, 7 and 8). Encouraged by these, a series of other Lewis acids, such as $\mathrm{FeCl}_{3}, \mathrm{Yb}(\mathrm{OTf})_{3}$, $\mathrm{Cu}(\mathrm{OTf})_{2}$ and $\operatorname{In}(\mathrm{OTf})_{3}$, were tested (entries 9-12): they could improve the reaction, but were less effective than $\mathrm{Fe}(\mathrm{OTf})_{3}$. Notably, the use of other bases, $\mathrm{Na}_{2} \mathrm{CO}_{3}$ or $\mathrm{Cs}_{2} \mathrm{CO}_{3}$, instead of $\mathrm{Ag}_{2} \mathrm{CO}_{3}$, resulted in no formation of product 4 (entries 13 and 14), suggesting that $\mathrm{Ag}_{2} \mathrm{CO}_{3}$ may act as an oxidant and a catalyst, not a base. Notably, the reported efficient oxidative systems, $t \mathrm{BuOO} t \mathrm{Bu}$ di-tert-butyl peroxide $(\mathrm{DTBP})^{42-55}$ or $\mathrm{Ag}_{2} \mathrm{CO}_{3} / \mathrm{K}_{2} \mathrm{~S}_{2} \mathrm{O}_{8}$ (refs 60-67) displayed rather lower activity for the reaction (entries 15 and 16). We found that the reaction was sensitive to the temperatures (entries 17 and 18): a lower temperature $\left(100^{\circ} \mathrm{C}\right)$ had a negative effect on the reaction, whereas a higher temperature $\left(130^{\circ} \mathrm{C}\right)$ did not improve the yield compared with the results at $120^{\circ} \mathrm{C}$. Gratifyingly, the reaction could be successfully performed in $\mathrm{PhCF}_{3}$ medium (entry 19).

Substrate scope with amines and amides. We next explored the scope of this $\mathrm{Ag}_{2} \mathrm{CO}_{3}$-mediated 1,2-carboamination protocol under the optimal reaction conditions with regard to alkenes $\mathbf{1}$, nitriles 2 and amines 3 (Tables 2 and 3). We first turned our attention to investigate the applicability of the optimal conditions in the reaction with various amines $\mathbf{3 b}-\mathbf{m}$ in the presence of alkene 1a and acetonitrile $\mathbf{2 a}$ (Table 2). The resulted indicated that a wide range of secondary and primary amines $3 \mathbf{b}-\mathbf{j}$ were smoothly converted to the desired products $\mathbf{5 - 1 3}$ in moderate to good yields. $N$-Methyl-1-phenylmethanamine (3b) was viable to furnish 5 with $89 \%$ yield in the presence of $\mathrm{Fe}(\mathrm{OTf})_{3}$ and $\mathrm{Ag}_{2} \mathrm{CO}_{3}$. For other amines $\mathbf{3} \mathbf{c}-\mathbf{j}$, however, $\mathrm{Fe}(\mathrm{OTf})_{3}$ displayed less efficient than $\mathrm{FeCl}_{3}$ (products 6-13): although treatment of alkene 1a with nitrile $2 \mathrm{a}$, diisopropylamine $(\mathbf{3 c}), \mathrm{Fe}(\mathrm{OTf})_{3}$ and $\mathrm{Ag}_{2} \mathrm{CO}_{3}$ afforded 6 in $56 \%$ yield, the use of $\mathrm{FeCl}_{3}$ instead of $\mathrm{Fe}(\mathrm{OTf})_{3}$ enhanced the yield to $66 \%$. Similarly, the yield of 10 from the reaction with morpholine (3g) increased from 74 to $83 \%$ when using $\mathrm{FeCl}_{3}$ instead of $\mathrm{Fe}(\mathrm{OTf})_{3}$. To our delight, the optimal
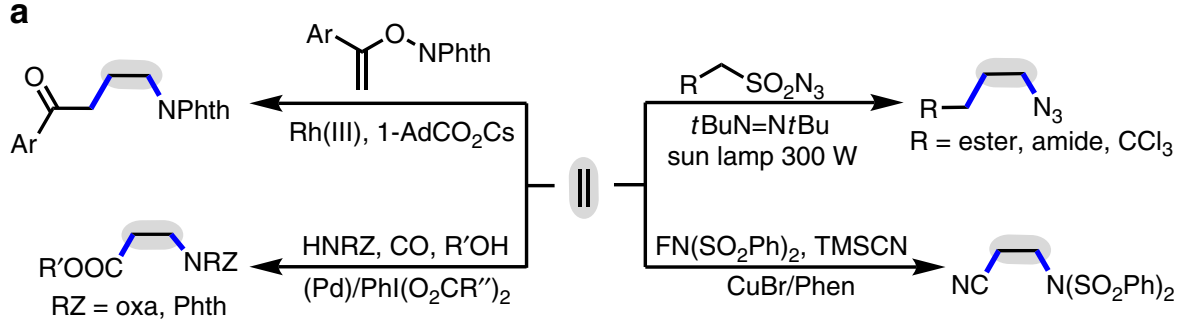

b

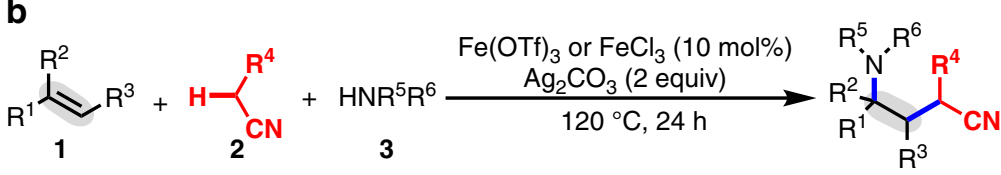

Figure 1 | 1,2-Carboamination of alkenes. (a) Previous work for 1,2-carboamination of alkenes ${ }^{33-36}$. (b) Our radical-mediated three-component, oxidative carboamination between alkenes, alkyl nitriles and amines using a $\mathrm{C}-\mathrm{H}$ oxidative functionalization. 
Table 1 | Screening of optimal reaction conditions.

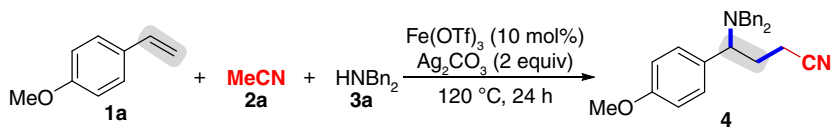

\begin{tabular}{|c|c|c|}
\hline Entry & Variation from the optimal conditions & Yield $(\%)^{\star}$ \\
\hline 1 & None & 82 \\
\hline 2 & Without $\mathrm{Fe}(\mathrm{OTf})_{3}$ & 33 \\
\hline 3 & Without $\mathrm{Ag}_{2} \mathrm{CO}_{3}$ & 0 \\
\hline 4 & $\mathrm{Ag}_{2} \mathrm{O}$ instead of $\mathrm{Ag}_{2} \mathrm{CO}_{3}$ & 34 \\
\hline 5 & $\mathrm{AgOAc}$ instead of $\mathrm{Ag}_{2} \mathrm{CO}_{3}$ & 15 \\
\hline 6 & $\mathrm{AgNO}_{3}$ instead of $\mathrm{Ag}_{2} \mathrm{CO}_{3}$ & 6 \\
\hline 7 & $\mathrm{Ag}_{2} \mathrm{CO}_{3}$ (1 equiv) & 53 \\
\hline 8 & $\mathrm{Ag}_{2} \mathrm{CO}_{3}$ (3 equiv) & 80 \\
\hline 9 & $\mathrm{FeCl}_{3}$ instead of $\mathrm{Fe}(\mathrm{OTf})_{3}$ & 68 \\
\hline 10 & $\mathrm{Yb}(\mathrm{OTf})_{3}$ instead of $\mathrm{Fe}(\mathrm{OTf})_{3}$ & 68 \\
\hline 11 & $\mathrm{Cu}(\mathrm{OTf})_{2}$ instead of $\mathrm{Fe}(\mathrm{OTf})_{3}$ & 41 \\
\hline 12 & $\ln (\mathrm{OTf})_{3}$ instead of $\mathrm{Fe}(\mathrm{OTf})_{3}$ & 63 \\
\hline 13 & $\mathrm{Na}_{2} \mathrm{CO}_{3}$ instead of $\mathrm{Ag}_{2} \mathrm{CO}_{3}$ & 0 \\
\hline 14 & $\mathrm{Cs}_{2} \mathrm{CO}_{3}$ instead of $\mathrm{Ag}_{2} \mathrm{CO}_{3}$ & 0 \\
\hline 15 & $(t \mathrm{BuO})_{2}$ instead of $\mathrm{Ag}_{2} \mathrm{CO}_{3}$ & trace \\
\hline $16^{\dagger}$ & $\mathrm{Ag}_{2} \mathrm{CO}_{3} / \mathrm{K}_{2} \mathrm{~S}_{2} \mathrm{O}_{8}$ instead of $\mathrm{Ag}_{2} \mathrm{CO}_{3}$ & trace \\
\hline 17 & At $100^{\circ} \mathrm{C}$ & 52 \\
\hline 18 & At $130^{\circ} \mathrm{C}$ & 80 \\
\hline $19 \ddagger$ & $\mathrm{MeCN}(0.2 \mathrm{ml} ; 3.85 \mathrm{mmol})$ & 78 \\
\hline
\end{tabular}

Experiments were performed with $\mathbf{1 a}(0.3 \mathrm{mmol}), \mathrm{MeCN} \mathbf{2 a}(2 \mathrm{ml}), \mathrm{Bn}_{2} \mathrm{NH}$ 3a (2 equiv), $\mathrm{Fe}(\mathrm{OTf})_{3}(10 \mathrm{~mol} \%), \mathrm{Ag}_{2} \mathrm{CO}_{3}$ (2 equiv), $120^{\circ} \mathrm{C}$ and $24 \mathrm{~h}$.

${ }^{*}$ Average isolated yield twice.

$\uparrow \mathrm{Ag}_{2} \mathrm{CO}_{3}\left(2 \mathrm{~mol} \%\right.$ ) and $\mathrm{K}_{2} \mathrm{~S}_{2} \mathrm{O}_{8}$ (2 equiv).

$\ddagger \mathrm{PhCF}_{3}(1.8 \mathrm{ml})$

Table 2 | Variation of the alkyl nitriles (2) and amines (3).
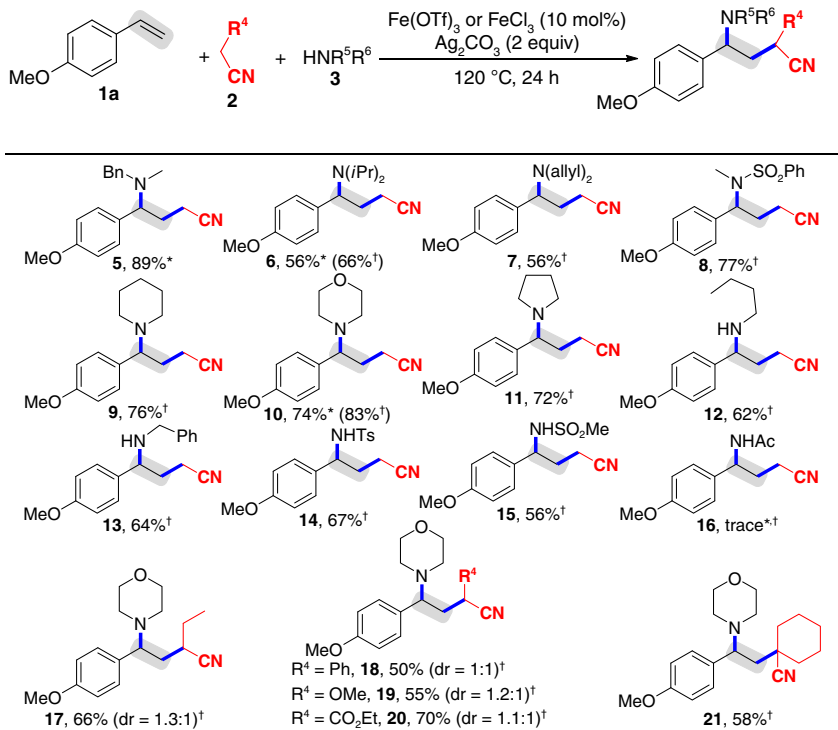

Experiments were performed with $\mathbf{1 a}(0.3 \mathrm{mmol})$, nitrile $\mathbf{2}(2 \mathrm{ml})$, amine $\mathbf{3}$ (2 equiv), [Fe] $(10 \mathrm{~mol} \%), \mathrm{Ag}_{2} \mathrm{CO}_{3}$ (2 equiv), $120^{\circ} \mathrm{C}, 24 \mathrm{~h}$. The $\mathrm{dr}$ value is given in parentheses as determined by ${ }^{1} \mathrm{H}$ NMR analysis of the crude product.

*Using $\mathrm{Fe}(\mathrm{OTf})_{3}$.

$\dagger$ Using $\mathrm{FeCl}_{3}$.

conditions were compatible with sulfonamides $\mathbf{3 e}, \mathbf{3 k}$ and $\mathbf{3 l}$, giving products 8, 14 and 15 in high yields. Unfortunately, attempt to difunctionalization with acetamide $3 \mathrm{~m}$ failed to build 1,2-carboamination product $\mathbf{1 6}$.
Table 3 | Variation of the alkenes (1).

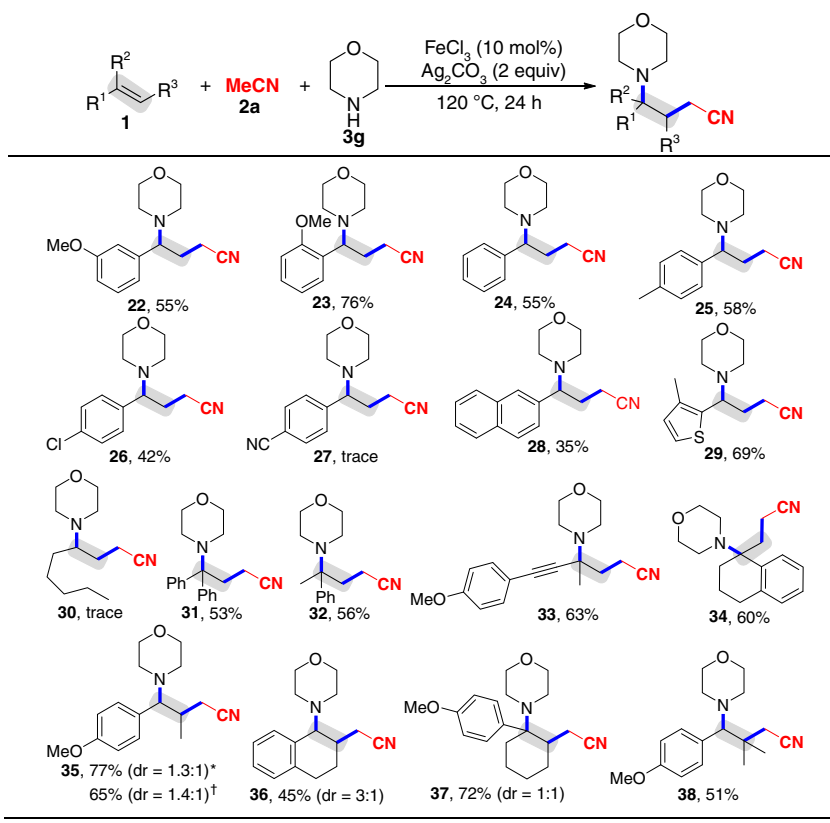

Experiments were performed with $\mathbf{1}\left(0.3 \mathrm{mmol}\right.$ ), nitrile $\mathbf{2 a}(2 \mathrm{ml})$, amine $\mathbf{3} \mathbf{g}$ ( 2 equiv), $\mathrm{FeCl}_{3}$ (10 mol\%), $\mathrm{Ag}_{2} \mathrm{CO}_{3}$ (2 equiv), $120^{\circ} \mathrm{C}, 24 \mathrm{~h}$. The $\mathrm{dr}$ value is given in parentheses as determined by ${ }^{1} \mathrm{H}$ NMR analysis of the crude product.

*Using (E)-1-methoxy-4-(prop-1-en-1-yl)benzene (10)

†Using (Z)-1-methoxy-4-(prop-1-en-1-yl)benzene (1p)

Subsequently, the scope of alkyl nitriles 2 was exploited in the presence of alkene 1a, morpholine $3 \mathrm{~g}, \mathrm{FeCl}_{3}$ and $\mathrm{Ag}_{2} \mathrm{CO}_{3}$ (Table 2). In the case of butyronitrile $\mathbf{2} \mathbf{b}$, the reaction afforded 17 in $66 \%$ yield. Gratifyingly, the reaction was well tolerated of various acetonitriles $2 \mathrm{c}-\mathbf{e}$ bearing a $\mathrm{Ph}$ group, a $\mathrm{MeO}$ group or a $\mathrm{CO}_{2}$ Et group at the $\alpha$ position, generating $\mathbf{1 8}-\mathbf{2 0}$ in $50-70 \%$ yields. An interesting observation was that secondary alkyl nitrile 2f containing a cyclohexyl ring also proceeded the reaction and resulted in the formation of $\mathbf{2 1}$ in $58 \%$ yield.

Substrate scope with alkenes. The optimal conditions were applicable to an array of alkenes $\mathbf{1 b}-\mathbf{f}, \mathbf{1 h}-\mathbf{i}$ and $\mathbf{1 k}-\mathbf{s}$ (products 22-26, 28-29 and 31-38), but electron-withdrawing aryl alkene $\mathbf{1 g}$ and simple aliphatic alkene, namely oct-1-ene $(\mathbf{1 j})$, had no reactivity (products 27 and 30; Table 3). Initially, the substitution effect of the aryl ring at the terminal alkenes were examined: several substituted aryl rings, such as $m-\mathrm{MeOC}_{6} \mathrm{H}_{4}$, $o-\mathrm{MeOC}_{6} \mathrm{H}_{4}, \mathrm{C}_{6} \mathrm{H}_{5}, p-\mathrm{MeC}_{6} \mathrm{H}_{4}, m-\mathrm{MeC}_{6} \mathrm{H}_{4}$, naphthalen-2-yl and 3-methylthiophen-2-yl, were perfectly tolerated, and both the electronic nature of the aryl group and the substituent position on the aryl group had an impact on the reactivity (products 22-29). Using $m$-methoxystyrene (1b), for example, afforded 22 in 55\% yield, whereas bulky $o$-methoxystyrene (1c) furnished 23 in 76\% yield. Alkene 1f having a weak electron-deficient $4-\mathrm{ClC}_{6} \mathrm{H}_{4}$ group successfully underwent the 1,2-alkylamination reaction to offer 26, albeit in a diminished yield. However, alkene $1 \mathrm{~g}$ having a strong electron-deficient $4-\mathrm{CNC}_{6} \mathrm{H}_{4}$ group had no reactivity (product 27). Gratifyingly, the optimal conditions were consistent with 1,1-disubstituted alkenes, including 1,1-diphenylethylene (1k), prop-1-en-2-ylbenzene (11), 1-methoxy-4-(3-methylbut-3-en-1-yn1-yl)benzene (1 $\mathbf{m})$ and 1-methylene-1,2,3,4-tetrahydronaphthalene (1n), generating 31-34 with concomitant formation of a quaternary carbon centre. A particularly attractive feature of this 1,2-alkylamination is the ability to enable the conversion of 
a<smiles>[CH+]=C(C(=C)C1CC1)c1ccccc1</smiles>

b

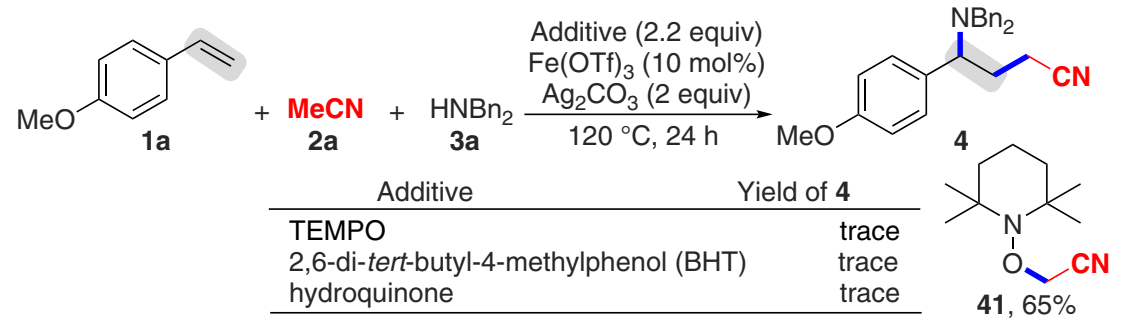

C

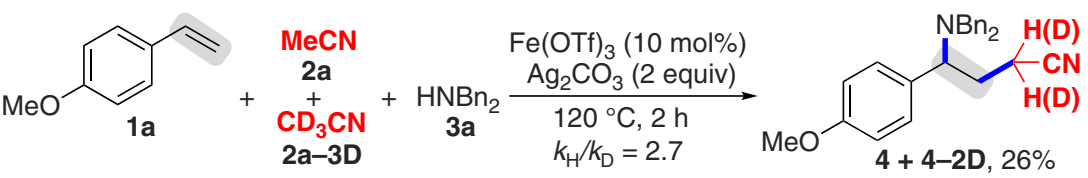

d

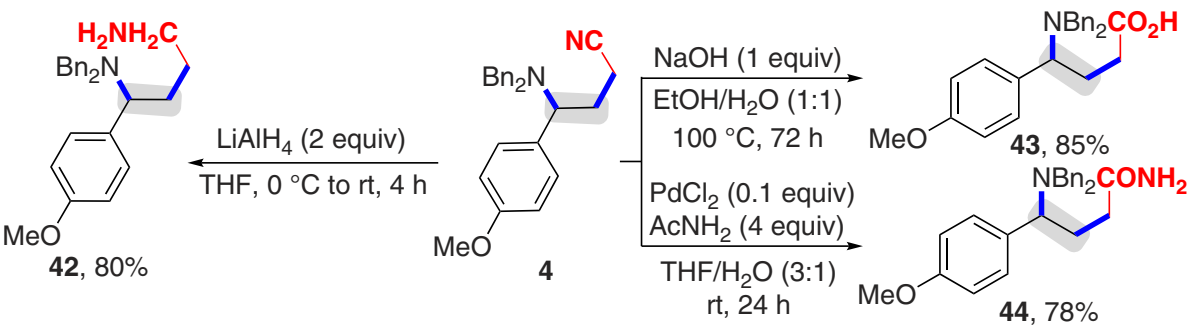

Figure 2 | Control experiments and utilizations of product 4. (a) Radical testing experiment based on the selectivity. (b) Trapping experiments with a stoichiometric amount of radical inhibitors. (c) Kinetic isotopic effect (KIE) study. (d) Synthetic utilizations.

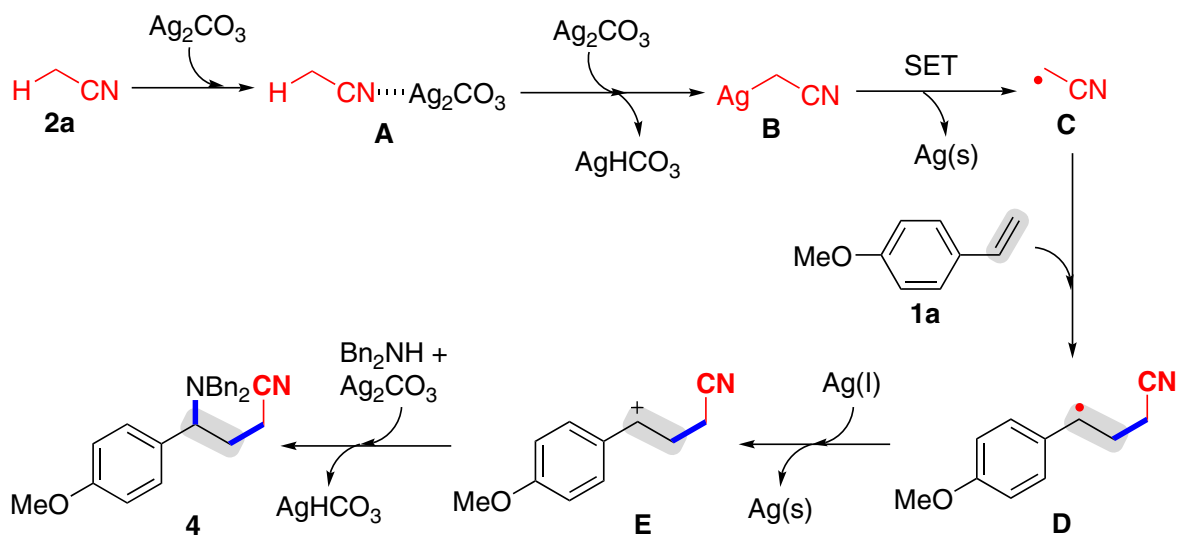

Figure 3 | Possible mechanism. The alkyl radical $\mathbf{C}$ is generated from decomposition of the $\mathrm{AgCH}_{2} \mathrm{CN}$ intermediate $\mathbf{B}$ via single-electron transfer. Subsequently, addition of the alkyl radical $\mathbf{C}$ across the $\mathrm{C}-\mathrm{C}$ double and oxidative amination afford product $\mathbf{4}$.

di- and trisubstituted internal alkenes 1o-s to diverse complex products 35-38 in moderate to good yields. It was noted that the reaction of (E)-1-methoxy-4-(prop-1-en-1-yl)benzene (10) or (Z)-1-methoxy-4-(prop-1-en-1-yl)benzene (1p) had no retention of geometrical selectivity in the double bond (product 35 ), which supported a radical process.

Control experiments and mechanistic studies. Using (1-cyclopropylvinyl)benzene (1t) to react with nitrile $\mathbf{2 a}$ and amine $\mathbf{3 g}$, the 1,2-alkylarmination product 39 along with the mono alkylation/ringopening/cyclization product $\mathbf{4 0}$ was observed (Fig. 2a) ${ }^{55}$. Notably, the reaction of alkene $\mathbf{1 a}$ with nitrile $\mathbf{2} \mathbf{a}$ and amine $\mathbf{3} \mathbf{a}$ could not take place in the presence of a stoichiometric amount of radical inhibitors, such as 2,2,6,6-Tetramethyl-1-piperidinyloxy (TEMPO), 2,6-di-tert-butyl-4-methylphenol and hydroquinone (Fig. 2b).

In addition, under the optimal conditions nitrile $\mathbf{2 a}$ reacted with TEMPO afforded product 41. These results suggested that the current reaction is triggered by a free-radical process. The kinetic isotope effect experiment gave a large kinetic isotope effect value $\left(k_{\mathrm{H}} / k_{\mathrm{D}}=2.7\right)$, implying that the cleavage of the $\mathrm{C}\left(s p^{3}\right)-\mathrm{H}$ bond may be rate-limiting (Fig. $2 \mathrm{c}$ and for the detailed information, see Supplementary Fig. 39) ${ }^{37-55}$. Gratifyingly, product 4 were easily converted to 1,4-diamine 42, $\gamma$-amino acid 43 and $\gamma$-amino amide 44 in good yields (Fig. 2d) ${ }^{69,70}$.

Consequently, the mechanisms for the $\mathrm{Ag}_{2} \mathrm{CO}_{3}$-mediated 1,2-alkylamination reaction was proposed (Fig. 3) ${ }^{31-68}$. 
Coordination of the nitrogen atom in $\mathrm{MeCN}$ 2a with $\mathrm{AgCO}_{3}$ gives the intermediate $\mathbf{A}$, which sequentially reacts with $\mathrm{AgCO}_{3}$ to afford the $\mathrm{AgCH}_{2} \mathrm{CN}$ intermediate $\mathbf{B}$ and $\mathrm{AgHCO}_{3}$. The decomposition the $\mathrm{AgCH}_{2} \mathrm{CN}$ intermediate $\mathbf{B}$ readily takes place under heating to form the alkyl radical $\mathbf{C}$ (supported by the results of Fig. 2b), $\mathrm{AgHCO}_{3}$ and the $\mathrm{Ag}^{0}$ species $[\mathrm{Ag}(\mathrm{s})]$ through single electron transfer ${ }^{42-65}$. Subsequently, addition of the alkyl radical $\mathbf{C}$ across the $\mathrm{C}-\mathrm{C}$ double bond in alkene 1a produces the alkyl radical intermediate $\mathbf{D}$ (supported by the reaction of alkene 1t; Fig. 2a). Intermediate $\mathbf{D}$ is converted into the carbon-centered cation $\mathbf{E}$, followed by reaction with amine $\mathbf{3 a}$ affords the product $4, \mathrm{AgHCO}_{3}$ and the $\mathrm{Ag}^{0}$ species through a sequence of oxidation and nucleophilic addition ${ }^{64-68}$. Notably, the radical intermediates $\mathbf{C}$ and $\mathbf{D}$ can be stabilized by Lewis acids, thus improving the yields.

In summary, we have developed a silver-mediated intermolecular 1,2-alkylamination of alkenes with alkyl nitriles and amines involving $\mathrm{C}\left(s p^{3}\right)-\mathrm{H}$ oxidative radical functionalization for producing $\gamma$-amino alkyl nitriles. The generality of such an intermolecular 1,2-alkylamination reaction is demonstrated by a wide scope with respect to alkenes, alkyl nitriles and amines. The radical mechanism was also discussed according to the control experiments. Importantly, applications of the products, $\gamma$-amino alkyl nitriles, to prepare other valuable synthons have been examined. Currently, our laboratory is working to apply this $\mathrm{C}-\mathrm{H}$ oxidative radical functionalization strategy in synthesis.

\section{Methods}

General procedure for 1,2-carboamination of alkenes. To a Schlenk tube were added $\mathrm{Fe}(\mathrm{OTf})_{3}$ or $\mathrm{FeCl}_{3}(10 \mathrm{~mol} \%), \mathrm{Ag}_{2} \mathrm{CO}_{3}(0.6 \mathrm{mmol})$, alkene $1(0.3 \mathrm{mmol})$, amine $2(0.6 \mathrm{mmol})$ and $\mathrm{MeCN}(2 \mathrm{ml})$. Then the tube was recharged with argon and the mixture was stirred at $120^{\circ} \mathrm{C}$ for $24 \mathrm{~h}$. After cooling to room temperature, the mixture was filtered through a small plug of silica gel to remove the precipitate and washed with with EtOAc $(3 \times 10 \mathrm{ml})$. The solvent was then removed in vacuo and the residue was further purified by silica gel flash column chromatography $\left(10-40 \%\right.$ ethyl acetate/hexane $\left.+0.1 \% \mathrm{Et}_{3} \mathrm{~N}\right)$ to afford the desired product.

Data availability. The X-ray crystallographic coordinates for structures reported in this study have been deposited at the Cambridge Crystallographic Data Centre under deposition number 1453224 (4). These data can be obtained free of charge from The Cambridge Crystallographic Data Centre via www.ccdc.cam.ac.uk/ data_request/cif. All other data supporting the findings of this study are available within the article and its Supplementary Information file or from the authors upon reasonable request. For NMR spectra of the compounds in this article, see Supplementary Figs 1-39.

\section{References}

1. Patai, S. The Chemistry of Alkenes (Wiley Interscience, 1964).

2. Li, G., Chang, T.-T. \& Sharpless, B. K. Catalytic asymmetric aminohydroxylation (AA) of olefins. Angew. Chem. Int. Ed. Engl. 35, 451-454 (1996).

3. Wolfe, J. P. Stereoselective synthesis of saturated heterocycles via palladiumcatalyzed alkene carboetherification and carboamination reactions. Synlett 2008, 2913-2937 (2008)

4. Wolfe, J. P. Intramolecular alkoxycyanation and alkoxyacylation reactions: new types of alkene difunctionalizations for the construction of oxygen heterocycles. Angew. Chem. Int. Ed. 51, 10224-10225 (2012).

5. Romero, R. M., Woste, T. H. \& Muniz, K. Vicinal difunctionalization of alkenes with iodine(III) reagents and catalysts. Chem. Asian J. 9, 972-983 (2014).

6. Francesca, C. \& Goti, A. Metal-catalysed 1,2-diamination reactions. Nat. Chem. 1, 269-275 (2009).

7. Lucet, D., Gall, T. L. \& Mioskowski, C. The chemistry of vicinal diamines. Angew. Chem. Int. Ed. 37, 2580-2627 (1998).

8. de Figueiredo, R. M. Transition-metal-catalyzed diamination of olefins. Angew. Chem. Int. Ed. 48, 1190-1193 (2009).

9. Zhu, Y., Cornwall, R. G., Du, H., Zhao, B. \& Shi, Y. Catalytic diamination of olefins via N-N bond activation. Acc. Chem. Res. 47, 3665-3678 (2014).

10. Streuff, J., Höelmann, C. H., Nieger, M. \& Muñiz, K. Palladium(II)-catalyzed intramolecular diamination of unfunctionalized alkenes. J. Am. Chem. Soc. 127, 14586-14587 (2005).
11. Iglesias, A., Pérez, E. \& Muñiz, K. An Intermolecular palladium-catalyzed diamination of unactivated alkenes. Angew. Chem. Int. Ed. 49, 8109-8111 (2010).

12. Röben, C., Souto, J. A., González, Y., Lishchynskyi, A. \& Muñiz, K. Enantioselective metal-free diamination of styrenes. Angew. Chem. Int. Ed. 50, 9478-9482 (2011).

13. Martínez, C. \& Muñiz, K. Palladium-catalyzed vicinal difunctionalization of internal alkenes: diastereoselective synthesis of diamines. Angew. Chem. Int. Ed. 51, 7031-7034 (2012).

14. Zhang, B. \& Studer, A. Copper-catalyzed intermolecular aminoazidation of alkenes. Org. Lett. 16, 1790-1793 (2014).

15. Yuan, Y.-A., Lu, D.-F., Chen, Y.-R. \& Xu, H. Iron-catalyzed direct diazidation for a broad range of olefins. Angew. Chem. Int. Ed. 55, 534-538 (2016).

16. Alexanian, E. J., Lee, C. \& Sorensen, E. J. Palladium-catalyzed ring-forming aminoacetoxylation of alkenes. J. Am. Chem. Soc. 127, 7690-7691 (2005).

17. Liu, G. \& Stahl, S. S. Highly regioselective Pd-catalyzed intermolecular aminoacetoxylation of alkenes and evidence for cis-aminopalladation and $\mathrm{SN}_{2}$ C-O bond formation. J. Am. Chem. Soc. 128, 7179-7181 (2006).

18. Desai, L. V. \& Sanford, M. S. Construction of tetrahydrofurans by $\mathrm{Pd}^{\mathrm{II}} / \mathrm{Pd}^{\mathrm{IV}}$-catalyzed aminooxygenation of alkenes. Angew. Chem. Int. Ed. 46, 5737-5740 (2007).

19. Zhu, H., Chen, P. \& Liu, G. Pd-catalyzed intramolecular aminohydroxylation of alkenes with hydrogen peroxide as oxidant and water as nucleophile. J. Am. Chem. Soc. 136, 1766-1769 (2014).

20. Zhu, H., Chen, P. \& Liu, G. Palladium-catalyzed intramolecular aminoacetoxylation of unactivated alkenes with hydrogen peroxide as oxidant. Org. Lett. 17, 1485-1488 (2015).

21. Chen, C., Chen, P. \& Liu, G. Palladium-catalyzed intramolecular aminotrifluoromethoxylation of alkenes. J. Am. Chem. Soc. 137, 15648-15651 (2015).

22. Sun, X. et al. Mn-catalyzed highly efficient aerobic oxidative hydroxyazidation of olefins: a direct approach to $\beta$-azido alcohols. J. Am. Chem. Soc. 137, 6059-6066 (2015).

23. Rao, W.-H., Yin, X.-S. \& Shi, B.-F. Catalyst-controlled amino-versus oxy-acetoxylation of urea-tethered alkenes: efficient synthesis of cyclic ureas and isoureas. Org. Lett. 17, 3758-3761 (2015).

24. Legnani, L. \& Morandi, B. Direct catalytic synthesis of unprotected 2-amino-1-phenylethanols from alkenes by using iron(II) phthalocyanine. Angew. Chem. Int. Ed. 55, 2248-2251 (2016).

25. Wu, T., Yin, G. \& Liu, G. Palladium-catalyzed intramolecular aminofluorination of unactivated alkenes. J. Am. Chem. Soc. 131, 16354-16355 (2009).

26. Qiu, S., Xu, T., Zhou, J., Guo, Y. \& Liu, G. Palladium-catalyzed intermolecular aminofluorination of styrene. J. Am. Chem. Soc. 132, 2856-2857 (2010).

27. Yin, G., Wu, T. \& Liu, G. Highly selective palladium-catalyzed intramolecular chloroamination of unactivated alkenes by using hydrogen peroxide as an oxidant. Chem. Eur. J. 18, 451-455 (2012).

28. Bovino, M. T. \& Chemler, S. R. Catalytic enantioselective alkene aminohalogenation/cyclization involving atom transfer. Angew. Chem. Int. Ed. 51, 3923-3927 (2012).

29. Kong, W., Feige, P., de Haro, T. \& Nevado, C. Regio- and enantioselective aminofluorination of alkenes. Angew. Chem. Int. Ed. 52, 2469-2473 (2013).

30. Zhang, H., Song, Y., Zhao, J., Zhang, J. \& Zhang, Q. Regioselective radical aminofluorination of styrenes. Angew. Chem. Int. Ed. 53, 11079-11083 (2014)

31. Mai, D. N. \& Wolfe, J. P. Asymmetric palladium-catalyzed carboamination reactions for the synthesis of enantiomerically enriched 2-(arylmethyl)- and 2-(alkenylmethyl)pyrrolidines. J. Am. Chem. Soc. 132, 12157-12159 (2010).

32. Faulkner, A., Scott, J. S. \& Bower, J. F. An umpolung approach to alkene carboamination: palladium catalyzed 1,2-amino-acylation, -carboxylation, -arylation, -vinylation, and -alkynylation. J. Am. Chem. Soc. 137, 7224-7230 (2015).

33. Piou, T. \& Rovis, T. Rhodium-catalysed syn-carboamination of alkenes via a transient directing group. Nature 527, 86-90 (2015).

34. Cheng, J., Qi, X., Li, M., Chen, P. \& Liu, G. Palladium-catalyzed intermolecular aminocarbonylation of alkenes: efficient access of $\beta$-amino acid derivatives. J. Am. Chem. Soc. 137, 2480-2483 (2015).

35. Weidner, K., Giroult, A., Panchaud, P. \& Renaud, P. Efficient carboazidation of alkenes using a radical desulfonylative azide transfer process. J. Am. Chem. Soc. 132, 17511-17515 (2010)

36. Zhang, H. et al. Copper-catalyzed intermolecular aminocyanation and diamination of alkenes. Angew. Chem. Int. Ed. 52, 2529-2533 (2013).

37. Liu, C., Zhang, H., Shi, W. \& Lei, A. Bond formations between two nucleophiles: transition metal catalyzed oxidative cross-coupling reactions. Chem. Rev. 111, 1780-1824 (2011).

38. Xie, Y.-X., Song, R.-J., Xiang, J.-N. \& Li, J.-H. Transition metal-catalyzed C-H oxidation reactions. Chin. J. Org. Chem. 32, 1555-1567 (2012).

39. Zhang, C., Tang, C. \& Jiao, N. Recent advances in copper-catalyzed dehydrogenative functionalization via a single electron transfer (SET) process. Chem. Soc. Rev. 41, 3464-3484 (2012). 
40. Girard, S. A., Knauber, T. \& Li, C.-J. The cross-dehydrogenative coupling of $\mathrm{Csp}^{3}$-bonds: a versatile strategy for $\mathrm{C}-\mathrm{C}$ bond formations. Angew. Chem. Int. Ed. 53, 74-100 (2014).

41. Song, R.-J., Liu, Y., Xie, Y.-X. \& Li, J.-H. Difunctionalization of acrylamides through C-H oxidative radical coupling: new approaches to oxindoles. Synthesis 47, 1195-1209 (2015).

42. Wu, T., Mu, X. \& Liu, G.-S. Palladium-catalyzed oxidative arylalkylation of activated alkenes: dual C-H bond cleavage of an arene and acetonitrile. Angew. Chem. Int. Ed. 50, 12578-12581 (2011).

43. Wei, W.-T. et al. Synthesis of oxindoles by iron-catalyzed oxidative 1,2-alkylarylation of activated alkenes with an aryl $\mathrm{C}\left(\mathrm{sp}^{2}\right)-\mathrm{H}$ bond and a $\mathrm{C}\left(\mathrm{sp}^{3}\right)-\mathrm{H}$ bond adjacent to a heteroatom. Angew. Chem. Int. Ed. 52, 3638-3641 (2013).

44. Zhou, M.-B. et al. Oxidative 1,2-difunctionalization of activated alkenes with benzylic $\mathrm{C}\left(\mathrm{sp}^{3}\right)-\mathrm{H}$ bonds and aryl $\mathrm{C}\left(\mathrm{sp}^{2}\right)-\mathrm{H}$ bonds. Chem. Commun. 49, 10817-10819 (2013).

45. Zhou, S.-L., Guo, L.-N., Wang, H. \& Duan, X.-H. Copper-catalyzed oxidative benzylarylation of acrylamides by benzylic $\mathrm{C}-\mathrm{H}$ bond functionalization for the synthesis of oxindoles. Chem. Eur. J. 19, 12970-12973 (2013).

46. Wang, H., Guo, L.-N. \& Duan, X.-H. Silver-catalyzed oxidative coupling/cyclization of acrylamides with 1,3-dicarbonyl compounds. Chem. Commun. 49, 10370-10373 (2013).

47. Li, Z.-J., Zhang, Y., Zhang, L.-Z. \& Liu, Z.-Q. Free-radical cascade alkylarylation of alkenes with simple alkanes: highly efficient access to oxindoles via selective $\left(\mathrm{sp}^{3}\right) \mathrm{C}-\mathrm{H}$ and $\left(\mathrm{sp}^{2}\right) \mathrm{C}-\mathrm{H}$ bond functionalization. Org. Lett. 16, 382-385 (2014).

48. Li, J., Wang, Z., Wu, N., Gao, G. \& You, J. Radical cascade cyanomethylation of activated alkenes to construct cyano substituted oxindoles. Chem. Commun. 50, 15049-15051 (2014)

49. Chu, X.-Q., Xing, Z.-H., Meng, H., Xu, X.-P. \& Ji, S.-J. Copper-mediated radical alkylarylation of unactivated alkenes with acetonitrile leading to fluorenes and pyrroloindoles. Org. Chem. Front. 3, 165-169 (2016).

50. Li, Y., Liu, B., Li, H.-B., Wang, Q. \& Li, J.-H. Oxidative radical 1,2-alkylarylation of alkenes with $\alpha-\mathrm{C}\left(\mathrm{sp}^{3}\right)$ - $\mathrm{H}$ bonds of acetonitriles involving 1,2-aryl migration. Chem. Commun. 51, 1024-1026 (2015).

51. Chu, X.-Q., Meng, H., Zi, Y., Xu, X.-P. \& Ji, S.-J. Oxidative C( $\left.\mathrm{sp}^{3}\right)-\mathrm{H}$ functionalization of acetonitrile and alkanes with allylic alcohols under metal-free conditions. Org. Chem. Front. 2, 216-220 (2015).

52. Bunescu, A., Wang, Q. \& Zhu, J. Copper-catalyzed cyanomethylation of allylic alcohols with concomitant 1,2-aryl migration: efficient synthesis of functionalized ketones containing an $\alpha$-quaternary center. Angew. Chem. Int. Ed. 54, 3132-3135 (2015).

53. Bunescu, A., Wang, Q. \& Zhu, J. Synthesis of functionalized epoxides by copper-catalyzed alkylative epoxidation of allylic alcohols with alkyl nitriles. Org. Lett. 17, 1890-1893 (2015).

54. Liang, W., Chen, P. \& Liu, G. AgF-mediated dialkylation of activate alkenes: an efficient access to nitrile-containing spirooxindoles. Chin. J. Chem. 32, 681-684 (2014)

55. Bunescu, A., Wang, Q. \& Zhu, J. Copper-mediated/catalyzed oxyalkylation of alkenes with alkylnitriles. Chem. Eur. J. 20, 14633-14636 (2014).

56. Chatalova-Sazepin, C., Wang, Q., Sammis, G. M. \& Zhu, J. Copper-catalyzed intermolecular carboetherification of unactivated alkenes by alkyl nitriles and alcohols. Angew. Chem. Int. Ed. 54, 5443-5446 (2015).

57. Liao, Z. et al. Copper-catalyzed radical carbooxygenation: alkylation and alkoxylation of styrenes. Chem. Asian J. 10, 96-99 (2015).

58. Ha, T. M., Chatalova-Sazepin, C., Wang, Q. \& Zhu, J. Copper-catalyzed formal $[2+2+1]$ heteroannulation of alkenes, alkylnitriles, and water: method development and application to a total synthesis of $( \pm)$-Sacidumlignan D. Angew. Chem. Int. Ed. 55, 9249-9252 (2016).

59. Ha, T. M., Wang, Q. \& Zhu, J. Copper-catalysed cyanoalkylative cycloetherification of alkenes to 1,3-dihydroisobenzofurans: development and application to the synthesis of citalopram. Chem. Commun. 52, 11100-11103 (2016).
60. Zhou, M.-B. et al. Metal-free oxidative tandem coupling of activated alkenes with carbonyl $\mathrm{C}\left(\mathrm{sp}^{2}\right)-\mathrm{H}$ bonds and aryl $\mathrm{C}\left(\mathrm{sp}^{2}\right)-\mathrm{H}$ bonds using TBHP. Chem. Sci. 4, 2690-2694 (2013).

61. Fan, J.-H. et al. Iron-catalyzed oxidative arylmethylation of activated alkenes using a peroxide as the methyl source. Synlett 25, 657-660 (2014).

62. $\mathrm{Hu}, \mathrm{M}$. et al. Metal-free radical $[2+2+1]$ carbocyclization of benzene-linked 1,n-enynes: dual $\mathrm{C}\left(\mathrm{sp}^{3}\right)-\mathrm{H}$ functionalization adjacent to a heteroatom. Angew. Chem. Int. Ed. 54, 9577-9580 (2015).

63. Ouyang, X.-H., Song, R.-J., Hu, M., Yang, Y. \& Li, J.-H. Silver-mediated intermolecular 1,2-alkylarylation of styrenes with $\alpha$-carbonyl alkyl bromides and indoles. Angew. Chem. Int. Ed. 55, 3187-3191 (2016).

64. Harmata, M. Silver in Organic Chemistry (John Wiley \& Sons Inc., 2010).

65. He, C. et al. Silver-mediated oxidative C-H/C-H functionalization: a strategy to construct polysubstituted furans. J. Am. Chem. Soc. 134, 5766-5769 (2012).

66. Li, Z., Song, L. \& Li, C. Silver-catalyzed radical aminofluorination of unactivated alkenes in aqueous media. J. Am. Chem. Soc. 135, 4640-4643 (2013).

67. Wei, X.-H., Li, Y.-M., Zhou, A.-X., Yang, T.-T. \& Yang, S.-D Silver-catalyzed carboazidation of arylacrylamides. Org. Lett. 15, 4158-4161 (2013).

68. Liu, J. et al. Silver-catalyzed cross-coupling of isocyanides and active methylene compounds by a radical process. Angew. Chem. Int. Ed. 54, 10618-10622 (2015).

69. Rappoport, Z. The Chemistry of the Cyano Group (Wiley, 1970).

70. Maffioli, S. I., Marzorati, E. \& Marazzi, A. Mild and reversible dehydration of primary amides with $\mathrm{PdCl}_{2}$ in aqueous acetonitrile. Org. Lett. 7, 5237-5239 (2005).

\section{Acknowledgements}

We thank the Natural Science Foundation of China (numbers 21472039 and 21625203) and the Hunan Provincial Natural Science Foundation of China (number 13JJ2018).

\section{Author contributions}

Y.-Y.L. and X.-H.Y. contributed equally to this work. Y.-Y.L., X.-H.Y., S.L. and J.-H.L. conceived the project and wrote the manuscript. Y.-Y.L. and X.-H.Y performed the experiments. Y.-Y.L., X.-H.Y. and R.-J.S. analysed the data.

\section{Additional information}

Supplementary Information accompanies this paper at http://www.nature.com/ naturecommunications

Competing financial interests: The authors declare no competing financial interests.

Reprints and permission information is available online at http://npg.nature.com/ reprintsandpermissions/

How to cite this article: Liu, Y.-Y. et al. Oxidative 1,2-carboamination of alkenes with alkyl nitriles and amines toward $\gamma$-amino alkyl nitriles. Nat. Commun. 8, 14720 doi: $10.1038 /$ ncomms14720 (2017).

Publisher's note: Springer Nature remains neutral with regard to jurisdictional claims in published maps and institutional affiliations.

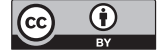

This work is licensed under a Creative Commons Attribution 4.0 International License. The images or other third party material in this article are included in the article's Creative Commons license, unless indicated otherwise in the credit line; if the material is not included under the Creative Commons license, users will need to obtain permission from the license holder to reproduce the material. To view a copy of this license, visit http://creativecommons.org/licenses/by/4.0/

(C) The Author(s) 2017 